\title{
Trends in Global Cloud Cover in Two Decades of HIRS Observations
}

\author{
Donald WyLie \\ Space Science and Engineering Center, University of Wisconsin-Madison, Madison, Wisconsin \\ DARREN L. JACKSON \\ Cooperative Institute for Research in Environmental Sciences, Boulder, Colorado \\ W. Paul Menzel \\ NOAA/NESDIS, Madison, Wisconsin \\ JOHN J. BATES \\ NOAA/ETL, Asheville, North Carolina
}

(Manuscript received 26 May 2004, in final form 20 October 2004)

\begin{abstract}
The frequency of cloud detection and the frequency with which these clouds are found in the upper troposphere have been extracted from NOAA High Resolution Infrared Radiometer Sounder (HIRS) polar-orbiting satellite data from 1979 to 2001. The HIRS/2 sensor was flown on nine satellites from the Television Infrared Observation Satellite-Next Generation (TIROS-N) through NOAA-14, forming a 22-yr record. Carbon dioxide slicing was used to infer cloud amount and height. Trends in cloud cover and high-cloud frequency were found to be small in these data. High clouds show a small but statistically significant increase in the Tropics and the Northern Hemisphere. The HIRS analysis contrasts with the International Satellite Cloud Climatology Project (ISCCP), which shows a decrease in both total cloud cover and high clouds during most of this period.
\end{abstract}

\section{Introduction}

There is interest in all factors of the earth's energy budget and their trends in time. Cloud cover is one variable that could magnify or reduce the warming effect of $\mathrm{CO}_{2}$ increases in the atmosphere, depending on the altitude and transparency of the cloud. The International Satellite Cloud Climatology Project (ISCCP; Schiffer and Rossow 1983; Rossow and Schiffer 1999) started analyzing cloud cover and cloud properties globally in 1983. The ISCCP used the spectral channels common to the operational weather satellites-the 0.5 $\mu \mathrm{m}$ visible channel and the $11-\mu \mathrm{m}$ longwave infrared window channel. These channels have been on the imaging sensors of the National Oceanic and Atmospheric

Corresponding author address: Dr. Donald Wylie, Space Science and Engineering Center, University of Wisconsin-Madison, 1225 West Dayton St., Madison, WI 53706.

E-mail: Don.Wylie@ssec.wisc.edu
Administration (NOAA) geostationary and polarorbiting satellites from the 1980s to the present time.

The High Resolution Infrared Radiometer Sounder (HIRS) instruments also were flown on the same NOAA polar-orbiting weather satellites during this time; ISCCP did not use the HIRS spectral channels because they were not available on all geostationary satellites. However, the longwave IR channels on HIRS provide an alternative way of detecting upper-tropospheric cirrus clouds that often elude the two ISCCP channels. Upper-tropospheric clouds that transmit terrestrial radiation appear warmer in the $11-\mu \mathrm{m}$ infrared window channel than the ambient temperature at their altitude; using only $11-\mu \mathrm{m}$ channel information, many are diagnosed incorrectly as lower altitude clouds. The ISCCP identifies these clouds and quantifies their IR transmission using the visible reflectance measurements. This limits detection of transmissive cirrus clouds to daylight only and to clouds with sufficient reflection difference with respect to their background. 
TABLE 1. Differences between the Wylie and Menzel (1999) HIRS analysis and this UW NOAA Pathfinder HIRS analysis.

\begin{tabular}{|c|c|c|}
\hline & Current UW Pathfinder & Earlier UW HIRS \\
\hline Record length & $22 \mathrm{yr}$ & $8 \mathrm{yr}$ \\
\hline Orbits processed & Both ascending and descending & Over land only; ascending 2 and 8 P.M. LT \\
\hline Width of scan swath & $18^{\circ}$ from nadir & $10^{\circ}$ from nadir \\
\hline Coverage & Contiguous FOVS over whole globe & $\begin{array}{l}\text { Every third element on every third line between } \\
60^{\circ} \mathrm{N} \text { and } 60^{\circ} \mathrm{S}\end{array}$ \\
\hline Basis of cloud mask & $\begin{array}{l}\text { Spatial and temporal variances of window channel } \\
\text { data plus } \mathrm{CO}_{2} \text { channel screening of thin cirrus }\end{array}$ & $\begin{array}{l}\text { Window channel comparison to NCEP } T_{\text {sfc }} \text { with } \\
\text { split window water vapor correction }\end{array}$ \\
\hline $\begin{array}{l}\text { Channel clear radiance } \\
\text { estimate }\end{array}$ & $\begin{array}{l}\text { Explicit forward radiance calculation with bias } \\
\text { correction }\end{array}$ & Interpolated from nearest clear FOV \\
\hline
\end{tabular}

Unlike the ISCCP, the longwave temperature sounding channels of HIRS do not depend on visible reflectance measurements and thus provide both a day and night cirrus detection capability. Therefore, an analysis of HIRS data was undertaken by the University of Wisconsin (UW) as a complement to the ISCCP.

The HIRS cloud-detection record from 1986 to 1998 was reported in Wylie et al. (1994) and Wylie and Menzel (1999). Comparison to the ISCCP showed that the HIRS reported $10 \%-15 \%$ more cloud cover than the ISCCP (Jin et al. 1996), mainly because of increased detection of radiatively thin cirrus clouds. Because of this increased detection of cloud cover, the NOAA Pathfinder program in conjunction with UW processed the full HIRS record extracted from NOAA's archives. This analysis is the topic of this paper. The HIRS/2 sensor was flown on Television Infrared Observation Satellite-Next Generation (TIROS-N) in 1978 and has been continued through the flight of NOAA-14 in 2001. The analysis approach of Wylie and Menzel (1999) was applied to the data, after a few changes that are summarized in the next section. A statistical summary of the UW NOAA Pathfinder analysis of the 22-yr $\mathrm{HIRS} / 2$ record is presented in the following sections.

\section{Cloud analysis method}

Cloud analyses are performed on HIRS data using the $\mathrm{CO}_{2}$ slicing method; the name alludes to the fact that each of the sounding channels views a different vertical layer of the atmosphere. Clouds are detected and their heights estimated by the amount that each $\mathrm{CO}_{2}$ channel (between 13 and $15 \mu \mathrm{m}$ ) is affected by the clouds. The analysis looks at spectrally adjacent pairings of the four HIRS channels, and cloud height solutions are derived for each of the pairings; the cloud height is that solution with the smallest total error in modeling the cloud signal on all four channels. This comparative method is simpler than the analysis of Stubenrauch et al. (1999a,b), which includes data from the Microwave Sounding Unit (MSU) and contains refinements for improving detection of low-altitude clouds. Marine stratus clouds along the eastern sides of oceans are usually below the altitude where the HIRS sounding channels are sensitive. Cloud-top altitudes in the UW NOAA Pathfinder analysis are inferred for these clouds using the blackbody temperature data of the $11-\mu \mathrm{m}$ window channel; this is less accurate than Stubenrauch et al. (1999a,b). The details of the UW HIRS cloud analysis were reported in Wylie and Menzel (1999) and are not repeated here. This UW NOAA Pathfinder analysis of HIRS data introduces some changes from the 1999 UW HIRS analysis; these are summarized in Table 1.

The largest change is in the determination of the cloud mask used to separate clear from cloudy HIRS fields of view (FOV). The UW NOAA Pathfinder analysis uses spatial and temporal variances in the 11$\mu \mathrm{m}$ window channel following Jackson and Bates (2001). Clear FOVs have low variances between neighboring FOVs and report the warmest data in each location over 5 days. This method of clear FOV identification is similar to that used in the ISCCP. The earlier UW HIRS study compared the $11-\mu \mathrm{m}$ window channel blackbody radiance temperature (after allowing for water vapor absorption using a split window correction) to the estimate of surface temperature $\left(T_{\text {sfc }}\right)$ found in the National Centers for Environmental Prediction (NCEP) daily operational analysis. The current UW NOAA Pathfinder analysis is independent of the NCEP surface temperature.

After establishing the cloud mask, measurements in clear FOVs are compared to forward model calculations of clear channel radiances using NCEP-National Center for Atmospheric Research (NCAR) reanalysis project temperature soundings. This is done to establish the biases in the clear radiance calculations with respect to the measurements. The $\mathrm{CO}_{2}$ slicing method requires an estimate of the clear radiance for each cloudy FOV in the radiative transfer equation solution for cloud 
TABle 2a. The distribution of UW NOAA Pathfinder HIRS cloud reports by cloud height and density from 1979 to 2001 . Here, $N \varepsilon$ refers to effective emissivity, and $\sigma$ refers to the corresponding visible optical depth (estimated to be twice the IR window optical depth). Over 76000000 HIRS observations from nine NOAA satellites are included. Percentages of all observations are reported.

\begin{tabular}{|c|c|c|c|c|}
\hline & \multicolumn{3}{|c|}{ Cloud density } & \\
\hline & Thin & Thick & Opaque & \\
\hline \multirow[t]{2}{*}{ Cloud level } & $N \varepsilon<0.5$ & $0.5<N \varepsilon<0.95$ & $N \varepsilon>0.95$ & All densities \\
\hline & $\sigma_{\text {vis }}<1.4$ & $1.4<\sigma_{\text {vis }}<6$ & $\sigma_{\mathrm{vis}}>6$ & \\
\hline $\operatorname{High}(<440 \mathrm{mb})$ & $15 \%$ & $15 \%$ & $3 \%$ & $33 \%$ \\
\hline Middle $(440-700 \mathrm{hPa})$ & $5 \%$ & $7 \%$ & $6 \%$ & $18 \%$ \\
\hline Low $(>700 \mathrm{hPa})$ & & $1 \%$ & $23 \%$ & $24 \%$ \\
\hline Total & $20 \%$ & $23 \%$ & $32 \%$ & $75 \%$ \\
\hline
\end{tabular}

height. The biases in the clear radiance calculation are averaged over 30 days in a uniformly spaced grid with cell sizes of $2.5^{\circ}$ latitude $\times 2.5^{\circ}$ longitude. Separate bias grids are used for the ascending and descending orbits on each satellite to isolate opposite parts of the diurnal cycle. The biases are applied in the radiative transfer equation solution of cloud height.

The UW NOAA Pathfinder analysis uses temperature and moisture soundings from the NCEP-NCAR Reanalysis Project; the earlier UW HIRS analysis used the operational analysis taken from NCEP daily files. The differences between these soundings are small, but the Reanalysis Project is expected to have better fields because it included more data than the NCEP operational analysis and used consistent methods over the 22 $\mathrm{yr}$ of this study. Changes made to improve the operational analysis can affect long-term trends. Reanalysis data are not affected by changes in the analysis model physics.

Forward calculations of clear radiances are made using the NCEP atmospheric transmission model (McMillin et al. 1995) that is derived from the Optical Path Transmission (OPTRAN) radiative transfer model. The earlier UW HIRS analysis used the transmission model from the International TIROS Operational Vertical Sounder (TOVS) Processing Project (ITPP). The differences between the two are very small.

The UW NOAA Pathfinder analysis includes more HIRS FOVs than the earlier UW HIRS analysis. All scan angle FOVs within $18^{\circ}$ of nadir are used; the earlier UW HIRS analysis sampled FOVs from every third pixel on every third line within $10^{\circ}$ of nadir. The UW Pathfinder also uses all measurements over land whereas the earlier UW HIRS analysis discarded the descending orbits at 2 and 8 A.M. (because the modelderived surface temperature did not track the diurnal cycle well and thus caused difficulties in the cloud mask). The inclusion of these orbits significantly improved coverage of continental areas. The UW NOAA
Pathfinder analysis also processes measurements in the polar regions; the earlier UW HIRS analysis was limited to measurements between $65^{\circ} \mathrm{N}$ and $65^{\circ} \mathrm{S}$ latitude.

Three passes are made through the HIRS data. The first pass identifies clear FOVs and generates a firstguess analysis of the biases in the forward calculation of clear radiances. The second pass through the data uses the $\mathrm{CO}_{2}$ channels to identify high clouds. All HIRS data are subjected to the second pass, including the FOVs marked clear by the cloud mask on the first pass. Any first-pass clear FOV is considered to be cloudy when two of the four $\mathrm{CO}_{2}$ channels from 13-15 $\mu \mathrm{m}$ have radiance observations more than $1 \mathrm{~mW} \mathrm{~m}{ }^{-2} \mathrm{sr}^{-1}$ $\left(\mathrm{cm}^{-1}\right)^{-1}$ colder than the forward-calculated clear FOV estimate after bias removal. About $2 \%$ of the FOVs change from clear to cloudy in this second pass. Using the clear FOVs remaining after the second pass through the data (i.e., after purging the clear FOVs of any FOVs in which the $\mathrm{CO}_{2}$ channels found clouds), the 30-day radiance bias averages are recalculated.

Thus, the method for estimating clear radiances is different from the earlier UW HIRS analysis in two ways. The first difference is the use of 30-day mean biases; the earlier UW HIRS analysis used only $12 \mathrm{~h}$ of data and was not always stable. The second difference is the use of $\mathrm{CO}_{2}$ channels to identify FOVs containing thin cirrus and to refine the cloud mask.

The $\mathrm{CO}_{2}$ slicing method is applied to the whole dataset in a third pass. This three-pass analysis differs from the two-pass analysis used in Wylie and Menzel (1999), where a clear radiance analysis was immediately followed by the cloud height analysis. The earlier HIRS analysis processed all data within 2 days of acquisition and did not revise clear radiance fields using the $\mathrm{CO}_{2}$ channel cloud detection. The data-processing decisions of the earlier HIRS analysis were based on the need to move large amounts of data through small communication channels. The UW NOAA Pathfinder analysis did not have this handicap. 
TABLE $2 \mathrm{~b}$. Table 2a statistics that have been corrected for the number of times the middle and low layers were actually observed by HIRS using a random overlap assumption.

\begin{tabular}{lcccc}
\hline \hline & \multicolumn{3}{c}{ Cloud density } \\
\cline { 2 - 4 } & Thin & Thick & Opaque & \\
\hline Cloud level & $N \varepsilon<0.5$ & $0.5<N \varepsilon<0.95$ & $N \varepsilon>0.95$ & All densities \\
& $\sigma_{\text {vis }}<1.4$ & $1.4<\sigma_{\text {vis }}<6$ & $\sigma_{\text {vis }}>6$ & $3 \%$ \\
High $(<440 \mathrm{mb})$ & $15 \%$ & $15 \%$ & $9 \%$ & $33 \%$ \\
Middle $(440-700 \mathrm{hPa})$ & $7 \%$ & $10 \%$ & $47 \%$ & $26 \%$ \\
Low $(>700 \mathrm{hPa})$ & $20 \%$ & $23 \%$ & $32 \%$ & $49 \%$ \\
Total & & $23 \%$ & $75 \%$ \\
\hline
\end{tabular}

\section{Global averages}

The UW NOAA Pathfinder HIRS global cloud reports are summarized in Table 2a. Clouds were found in $75 \%$ of the data. High clouds (over $440 \mathrm{hPa}$ ) were found in $33 \%$, and IR transmissive clouds were found in $43 \%$ of the data. Cloud frequencies are adjusted in Table $2 \mathrm{~b}$ to account for the fact that lower-cloud layers are not observed where higher clouds are found. The lower-cloud layers are only observed when higher clouds are not present. To approximate global lowercloud coverage, one can assume that the coverage of lower clouds is the same when the view is obstructed as when it is not (sometimes called a random overlap assumption). Cloud frequency statistics are reported both ways in the literature, with and without correction for higher-cloud blockage. The blockage-corrected statistics indicate that low-level clouds (below $700 \mathrm{hPa}$ ) are more common than high clouds with a $49 \%$ frequency of occurrence. These values are within $2 \%$ of those reported in Wylie and Menzel (1999).

The geographical distribution of clouds also follows Wylie and Menzel (1999) and is shown in Fig. 1. Clouds are most frequently found in the intertropical convergence zone (ITCZ) and the midlatitude storm belts of the North Atlantic, North Pacific, and Antarctic

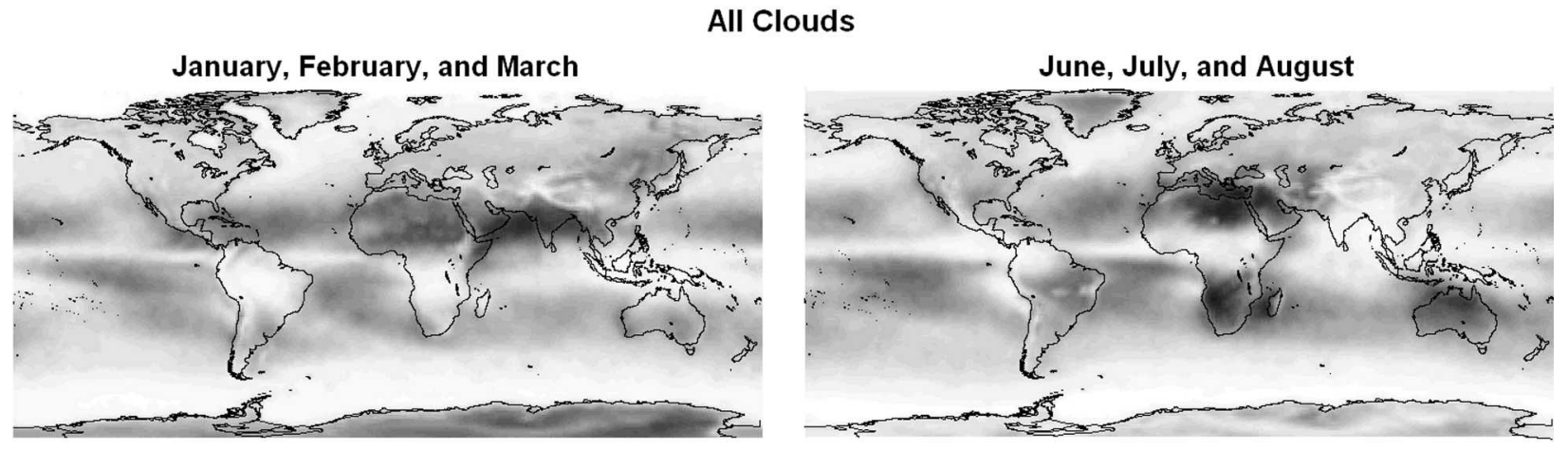

High Clouds
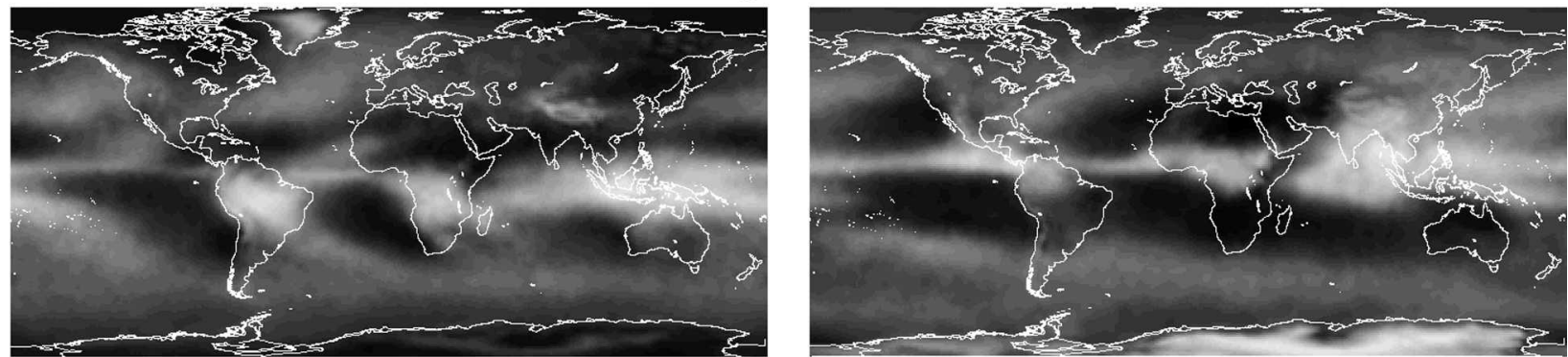

Frequency of Clouds $50 \%$

$100 \%$

FIG. 1. The frequency of all clouds and high clouds above $440 \mathrm{hPa}$ from 1979 to 2001 found in HIRS data during winter [Dec-Jan-Feb (DJF)] and summer [Jun-Jul-Aug (JJA)]. 
TABLE 3. The local time of the equator-crossing ascending node at the beginning and ending of the flights of each NOAA satellite in the 2 A.M./P.M. orbit.

\begin{tabular}{|c|c|c|c|c|c|c|}
\hline \multirow[b]{2}{*}{ Satellite } & \multicolumn{3}{|c|}{ Beginning of flight } & \multicolumn{3}{|c|}{ End of flight } \\
\hline & Month & Year & $\begin{array}{l}\text { Time } \\
\text { (LT) }\end{array}$ & Month & Year & $\begin{array}{l}\text { Time } \\
\text { (LT) }\end{array}$ \\
\hline$N O A A-5$ & Jan & 1979 & 1532 & Jan & 1981 & 1588 \\
\hline$N O A A-7$ & Jul & 1981 & 1451 & Jan & 1985 & 1593 \\
\hline$N O A A-9$ & Jan & 1985 & 1437 & Oct & 1988 & 1612 \\
\hline$N O A A-11$ & Nov & 1988 & 1371 & Dec & 1994 & 1728 \\
\hline NOAA-14 & Jan & 1995 & 1373 & Dec & 2001 & 1753 \\
\hline
\end{tabular}

Oceans. In between are the subtropical high pressure zones over the oceans and the subtropical deserts over land where clouds are less frequent. These features move north and south, following the sun with the seasons.

The outlines of the Rocky Mountains, Himalayas, and Tibetan Plateau also appear in Fig. 1. These are likely errors in the cloud retrieval system caused by high-altitude mountains.

\section{Time trends}

Time trends are reported for three latitude belts, $20^{\circ}-60^{\circ} \mathrm{N}, 20^{\circ}-60^{\circ} \mathrm{S}$, and the Tropics from $20^{\circ} \mathrm{S}$ to $20^{\circ} \mathrm{N}$. The time series are taken from the NOAA satellite in the 2 A.M./P.M. orbit; the 8 A.M./P.M. orbit has gaps of several months to $1.5 \mathrm{yr}$ in duration so it is treated
TABLE 4. The change in cloud frequency per hour of orbit drift. Units are cloud fraction per hour.

\begin{tabular}{lccccc}
\hline \hline & \multicolumn{3}{c}{ Orbit drift corrections } \\
\cline { 2 - 3 } \cline { 6 - 7 } & \multicolumn{2}{c}{ All clouds } & & \multicolumn{2}{c}{ High clouds } \\
\cline { 2 - 3 } \cline { 6 - 7 } & Land & Ocean & & Land & Ocean \\
\hline $20^{\circ}-60^{\circ} \mathrm{N}$ & -0.004 & 0.002 & & 0.007 & 0.004 \\
Tropics: $20^{\circ} \mathrm{S}-20^{\circ} \mathrm{N}$ & -0.010 & 0.006 & & 0.010 & 0.004 \\
$20^{\circ}-60^{\circ} \mathrm{S}$ & -0.013 & 0.003 & & 0.006 & 0.000 \\
\hline
\end{tabular}

separately. Cloud frequencies for the two orbits are similar; the more continuous 2 A.M./P.M. orbit is used to represent the trends found in this UW NOAA Pathfinder HIRS analysis. Monthly averages in each latitude belt are subdivided into separate time series for land and ocean areas. However, before calculating the time trends, two corrections must be applied.

\section{a. Corrections for orbit drift}

The local passage of the 2 A.M./P.M. satellites over the lifetime of each satellite drift as much as $3.8 \mathrm{~h}$ (see Table 3). To evaluate the effect of orbit drift, monthly means of cloud detection frequency for each satellite are plotted against the local time of passage (equator crossing time); the results are summarized in Table 4. The largest changes are found over land in the $20^{\circ}-60^{\circ} \mathrm{S}$ latitude belt (see Fig. 2), where the frequency of all clouds reported dropped by 0.0127 per hour of orbit drift. In the other regions, the cloud frequency changes

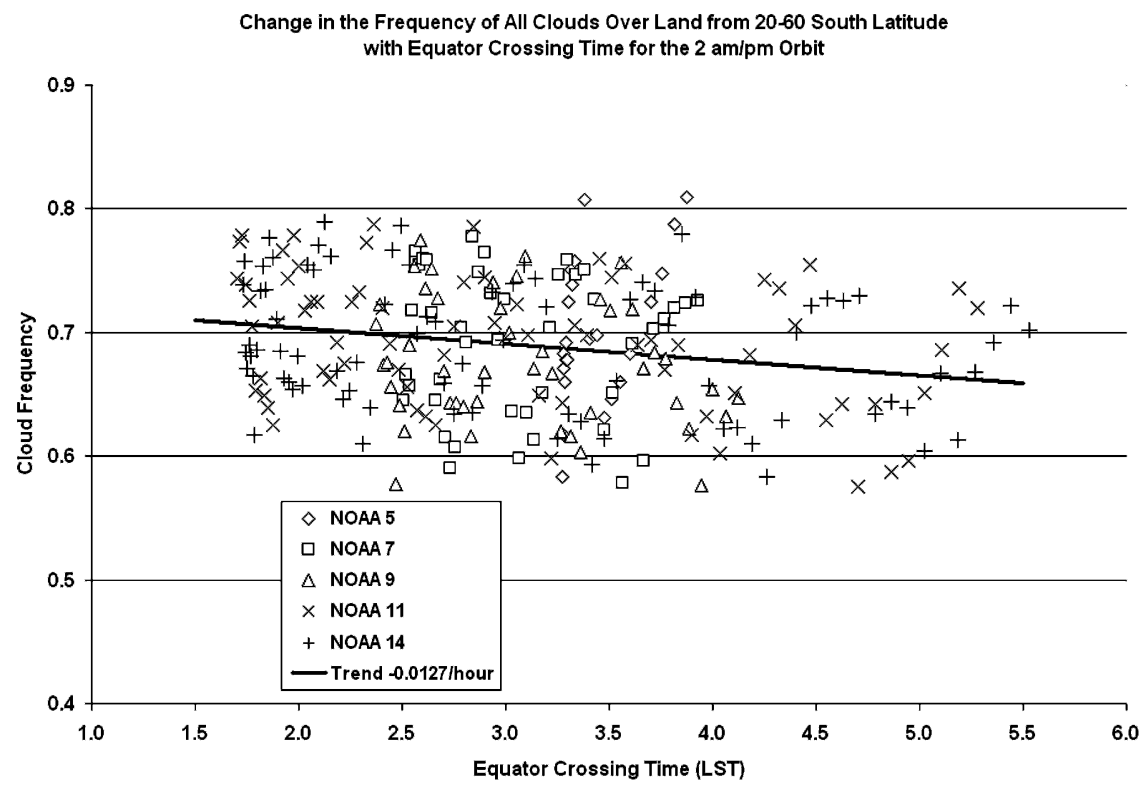

FIG. 2. The monthly average frequency of clouds over land as a function of the equator crossing time for each satellite in each month studied. 


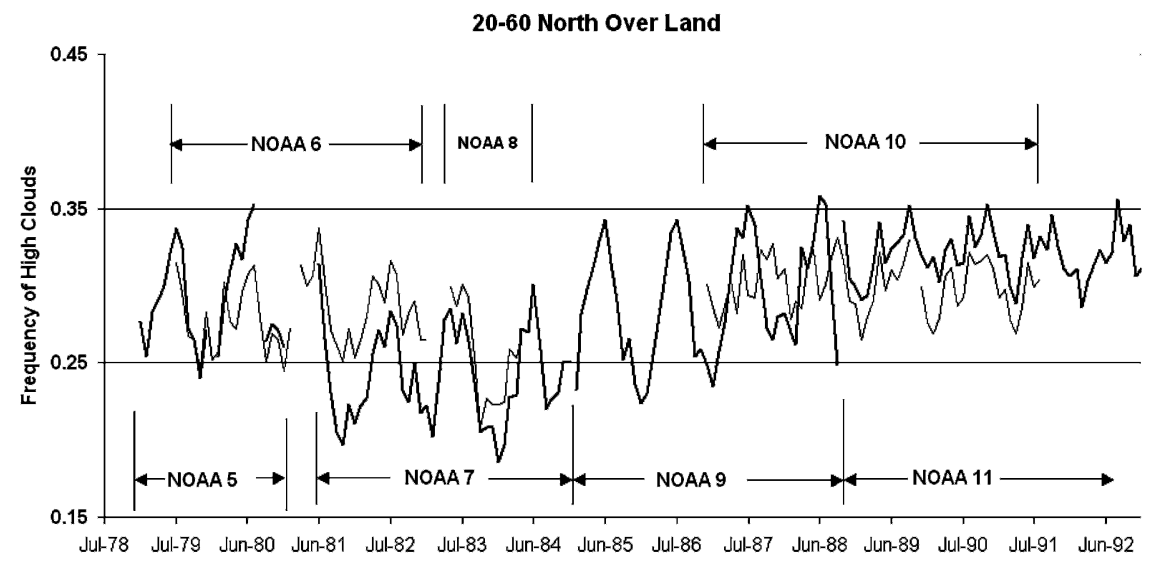

FIG. 3. The monthly average frequency of high clouds from $20^{\circ}$ to $60^{\circ} \mathrm{N}$ showing the time period of individual satellites.

were 0.01 or less per hour of orbit drift. Over land all cloud detection decreases with orbit drift, while over oceans detection increases with orbit drift. This may appear to defy conventional expectations of the diurnal cycle of clouds where cloud cover is expected to increase later in the day over land from solar heating. However, the diurnal cycle for most clouds over land follows the sun and peaks in early afternoon. As the satellite orbits drifted into the later afternoon, they sampled after the diurnal cycle peaks. High-cloud detection is found to increase with orbit drift significantly over land and much less over ocean. High cloud cover peaks later in the day because of cirrus generated by cumulonimbus clouds (Wylie and Woolf 2002); this is evident in these data.

These cloud frequencies are accumulated from both the day (descending) and night (ascending) orbits. For high clouds over land, the effect of orbit drift differs between day and night orbits. High-cloud reports decrease with orbit drift for the night overpass, while they increase for the day overpass. The daytime increase is stronger than the nighttime decrease (thus dominating the average shown in Fig. 2). This occurs in all latitude belts. Total cloud cover (all clouds of all altitudes) generally decreases for both the day and night overpasses with orbit drift.

The cloud trends shown in this paper are adjusted linearly so that all 2 A.M./P.M. satellites have the ascending node at 1400 local time (LT).

\section{b. Corrections for changing $\mathrm{CO}_{2}$ concentrations}

From 1979 to 2001, atmospheric concentrations of $\mathrm{CO}_{2}$ increased from 335 to $375 \mathrm{ppm}$. For this analysis, the $\mathrm{CO}_{2}$ concentration is assumed to be constant at 380 ppm to be consistent with NCEP's radiative transfer code. The amount of $\mathrm{CO}_{2}$ affects atmospheric transmission in the sounding channels used in the calculation of cloud altitude. To estimate the impact of an assumption of constant $\mathrm{CO}_{2}$ concentrations on our cloud trends, one month of HIRS data was reprocessed with transmission functions representative of a lower $\mathrm{CO}_{2}$ concentration of $335 \mathrm{ppm}$. To adjust the transmission function from high to low $\mathrm{CO}_{2}$ concentration, the exponential form of the transmittance function suggests that $\tau_{\text {dry }}(335, p, \mathrm{ch})=\tau_{\text {dry }}(380, p, \mathrm{ch})^{335 / 380}$, where $\tau_{\text {dry }}(380$, $p, \mathrm{ch})$ is the transmission for a higher $\mathrm{CO}_{2}$ concentration from pressure level $(p)$ to the top of the atmosphere for HIRS channel (ch) considering only dry air with $\mathrm{CO}_{2}$, and $\tau_{\text {dry }}(335, p, \mathrm{ch})$ is the same for lower $\mathrm{CO}_{2}$ concentration. The total transmission $(\tau)$ is the product of the dry-air transmission $\left(\tau_{\text {dry }}\right)$, the water vapor transmission $\left(\tau_{\mathrm{H} 2 \mathrm{O}}\right)$, and the ozone transmission $\left(\tau_{\mathrm{O} 3}\right)$ : thus $\tau(p, \mathrm{ch})=\tau_{\mathrm{dry}}(p, \mathrm{ch}) \times \tau_{\mathrm{H} 2 \mathrm{O}}(p, \mathrm{ch}) \times \tau_{\mathrm{O} 3}(p, \mathrm{ch})$.

Lower $\mathrm{CO}_{2}$ concentrations increase the atmospheric transmission, so radiation is detected from lower altitudes in the atmosphere. For January 2001, the clouds detected by NOAA-14 in the more transparent atmosphere $\left(\mathrm{CO}_{2}\right.$ at $\left.335 \mathrm{ppm}\right)$ are found to be lower by 13-50 $\mathrm{hPa}$; this results in HIRS reporting less high clouds than reported with the more opaque atmospheric transmission functions $\left(\mathrm{CO}_{2}\right.$ at $\left.380 \mathrm{ppm}\right)$. This implies that the frequencies of high-cloud detection in 1979 and the early 1980s are likely reported to be too large (using $\mathrm{CO}_{2}$ at $380 \mathrm{ppm}$ ) and that the trends for increasing high-cloud detection are larger than shown in the constant $\mathrm{CO}_{2}$ analysis. This effect was larger outside of the Tropics averaging an increase of 0.028 in the frequency of high clouds poleward of $20^{\circ}$ latitude equally in each hemisphere, while in the Tropics the increase in was only 0.018 . 
TABLE 5. The statistically significant trends in cloud frequency change per decade from 1985 to 2001.

\begin{tabular}{|c|c|c|c|c|c|c|}
\hline & \multicolumn{2}{|c|}{$20^{\circ}-60^{\circ} \mathrm{N}$} & \multicolumn{2}{|c|}{$20^{\circ} \mathrm{S}-20^{\circ} \mathrm{N}$} & \multicolumn{2}{|c|}{$20^{\circ}-60^{\circ} \mathrm{S}$} \\
\hline & Ocean & Land & Ocean & Land & Ocean & Land \\
\hline & \multicolumn{6}{|c|}{ HIRS uncorrected } \\
\hline High clouds & 0.013 & 0.014 & None & 0.017 & 0.014 & 0.021 \\
\hline \multirow[t]{2}{*}{ All clouds } & None & None & 0.018 & None & None & None \\
\hline & \multicolumn{6}{|c|}{ HIRS corrected } \\
\hline High clouds & 0.023 & 0.021 & None & 0.017 & 0.027 & 0.029 \\
\hline \multirow[t]{2}{*}{ All clouds } & None & None & 0.014 & None & None & None \\
\hline & \multicolumn{6}{|c|}{ ISCCP } \\
\hline High clouds & None & -0.015 & None & None & None & -0.020 \\
\hline All clouds & -0.042 & -0.031 & -0.037 & -0.021 & -0.017 & -0.010 \\
\hline
\end{tabular}

Each of the six time series was adjusted to represent a linear increase of $\mathrm{CO}_{2}$ from $335 \mathrm{ppm}$ in 1979 to 375 ppm in 2001.

\section{c. Corrections for anomalous satellites}

The corrected 22-yr trends in the UW NOAA Pathfinder HIRS detection show a dip in high-cloud frequency from 1982 to 1985 during the flight of NOAA-7. Figure 3 examines this period, showing the cloud-detection trends for each satellite individually. NOAA-7, in the 2 A.M./P.M. orbit, shows high-cloud frequencies that are lower than NOAA-5 before and NOAA-9 after. $N O A A-8$, in the 8 A.M./P.M. orbit, also shows a similar dip of lesser magnitude during this time along with an increase by its successor, NOAA-10. In the absence of an explanation for this dip, we did not use the
NOAA-5 and -7 data in calculation of trends. Thus, UW NOAA Pathfinder HIRS trends are reported for 19852001. Trends in the ISCCP data were calculated from its beginning of July 1983 through September 2001.

\section{d. Corrected cloud trends}

The corrected 16-yr trends in the UW NOAA Pathfinder HIRS detection of all clouds and high clouds are shown in Table 5. Statistically significant trends after removing the annual cycle are believed to be only those greater than 0.01 decade $^{-1}$. The UW NOAA Pathfinder HIRS and the ISCCP time series for $20^{\circ}-60^{\circ} \mathrm{N}$ latitude over land are shown in Fig. 4. The ISCCP shows a strong decrease in cloud cover $(-0.031$ decade $^{-1}$ ), while the HIRS shows no discernible change. For high clouds, HIRS and the ISCCP also disagree on

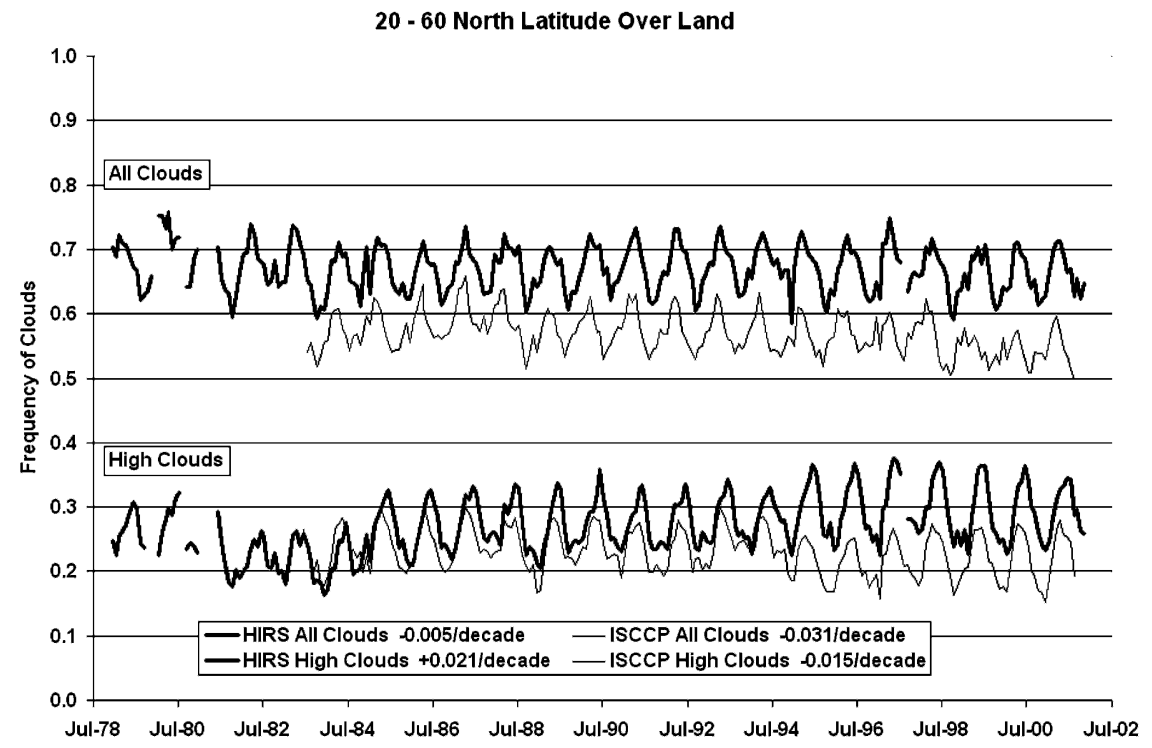

FIG. 4. The monthly average frequency of clouds and high clouds (above $440 \mathrm{hPa}$ ) from $20^{\circ}$ to $60^{\circ} \mathrm{N}$ latitude over land. 


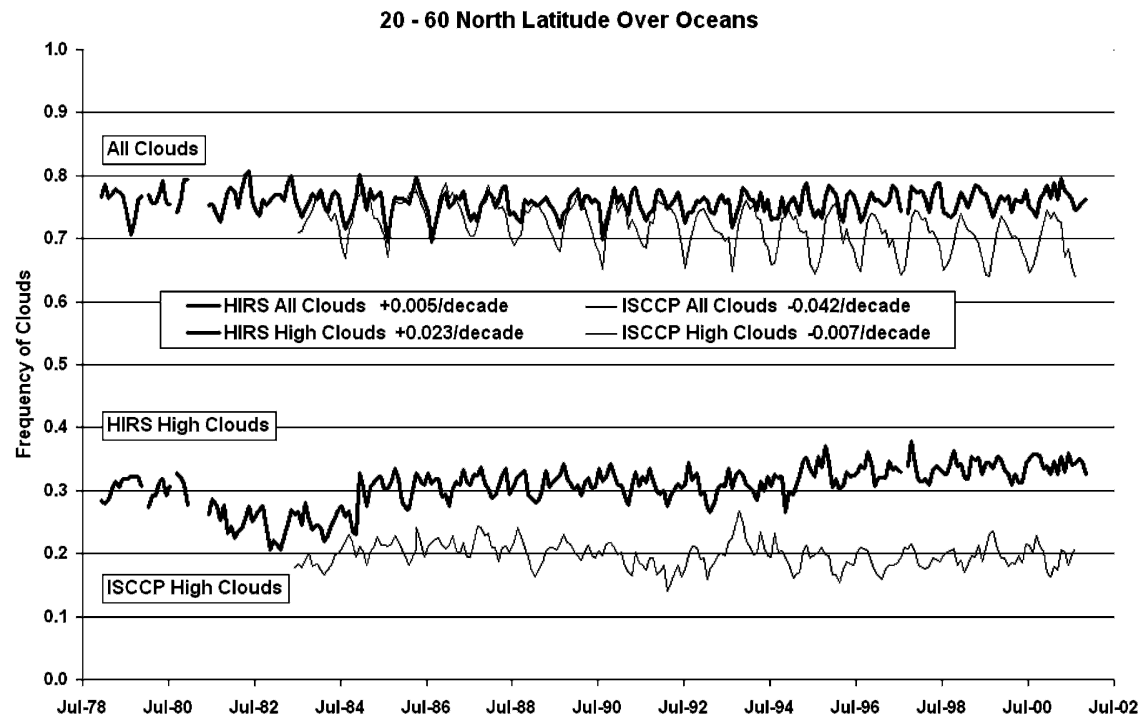

FIG. 5. The monthly average frequency of clouds from $20^{\circ}$ to $60^{\circ} \mathrm{N}$ over oceans.

the trends; the HIRS data show a modest increase $\left(0.021 \mathrm{decade}^{-1}\right)$, while the ISCCP shows a slight decrease $\left(-0.015\right.$ decade $\left.^{-1}\right)$.

Over oceans from $20^{\circ}$ to $60^{\circ} \mathrm{N}$ (Fig. 5), the trends are similar to the land data. The ISCCP shows a decreasing trend of total cloud cover of -0.042 decade $^{-1}$, while the HIRS trend is insignificant. For high clouds, HIRS finds an increasing trend of 0.023 decade $^{-1}$, while ISCCP shows no significant trend.

The same pattern in trends is found in the Tropics (Figs. 6 and 7). Over land, the ISCCP finds total cloud cover to decrease by -0.21 decade $^{-1}$, and the HIRS does not find a trend. HIRS finds high clouds over land to be increasing by 0.017 decade $^{-1}$, while ISCCP does not find any significant trend.

Over tropical oceans, the ISCCP finds a decrease of total cloud cover of -0.037 decade $^{-1}$. In this belt, the HIRS finds a small increasing trend of total cloud cover of 0.014 decade $^{-1}$. For high clouds, both HIRS and ISCCP trends are insignificant.

In the southern midlatitudes over land (Fig. 8), the ISCCP finds a slight decreasing trend in total cloud

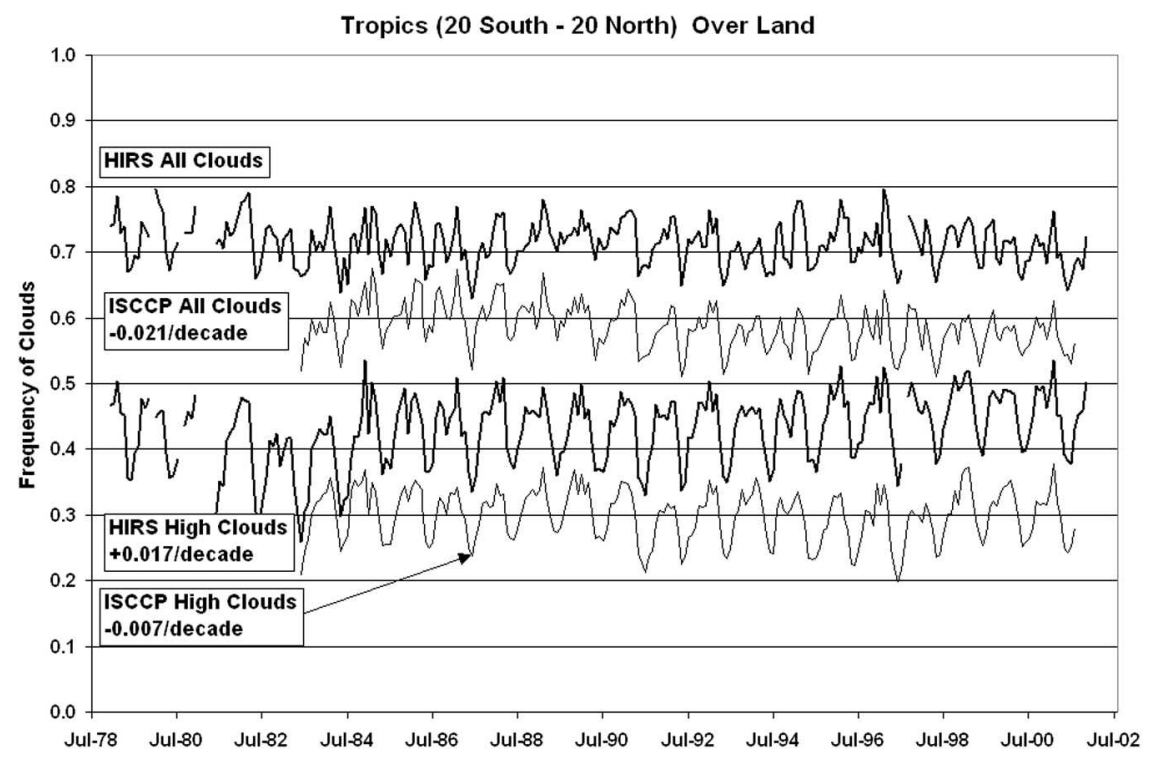

FIG. 6. The monthly average frequency of clouds from $20^{\circ} \mathrm{S}$ to $20^{\circ} \mathrm{N}$ over land. 


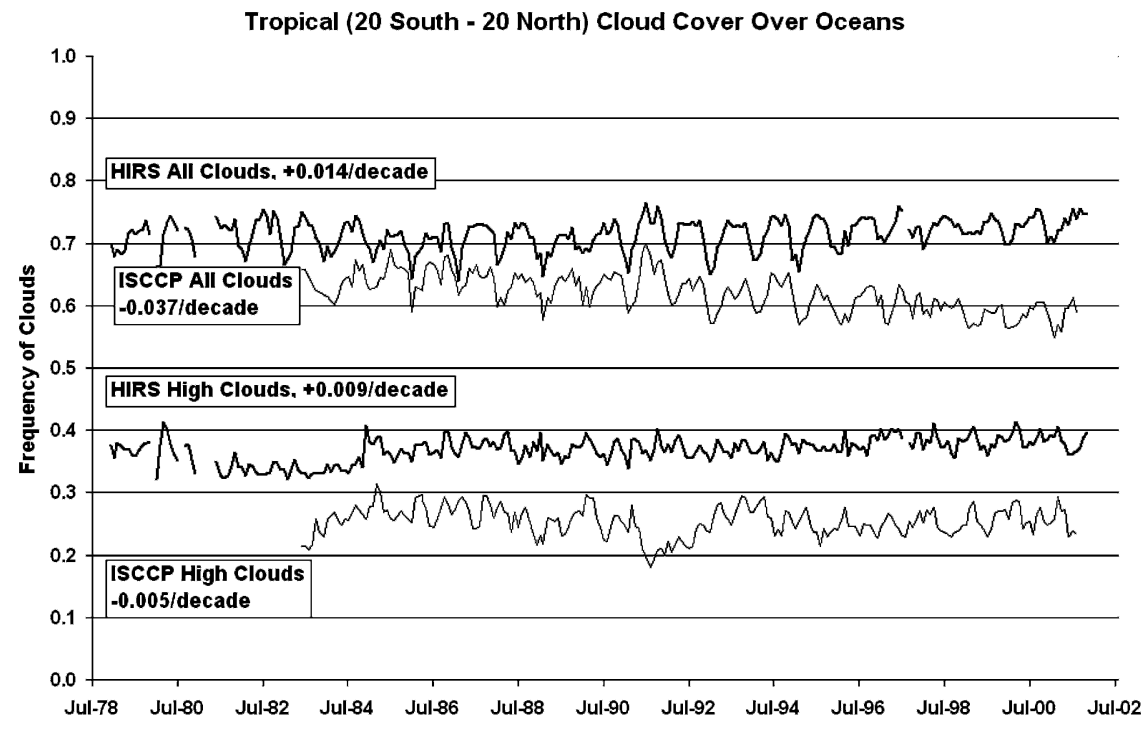

FIG. 7. Same as in Fig. 6, but over oceans.

cover of -0.010 decade $^{-1}$, and the HIRS finds no trend. But for high clouds, the ISCCP finds a significant decreasing trend of -0.020 decade $^{-1}$, which contrasts with the HIRS increasing trend of 0.029 decade $^{-1}$.

In southern midlatitudes over oceans (Fig. 9), the ISCCP finds a decreasing trend of total cloud cover of 0.017 decade $^{-1}$ where the HIRS does not find a trend. For high clouds, the same pattern occurs with HIRS finding an increasing trend of 0.027 decade $^{-1}$ and ISCCP not finding a trend.

In Fig. 10, the geographical locations of the cloud cover changes are studied using the difference of the average of the last $8 \mathrm{yr}(1993-2001)$ of the HIRS record subtracted from the average of the first 8 yr (1985-93). All clouds show their largest increases over tropical oceans in the Atlantic, the eastern tropical Pacific, and the northern Indian Oceans. Other small increases are found in Asia. Small areas of cloud cover decreases are found over oceans in the subtropics in both hemispheres. High clouds (Fig. 10b) show large increases in the Tropics and over central Asia, while small decreases are found in the southern subtropics. Large decreases in both the all-cloud and high-cloud categories are found over eastern Antarctica.

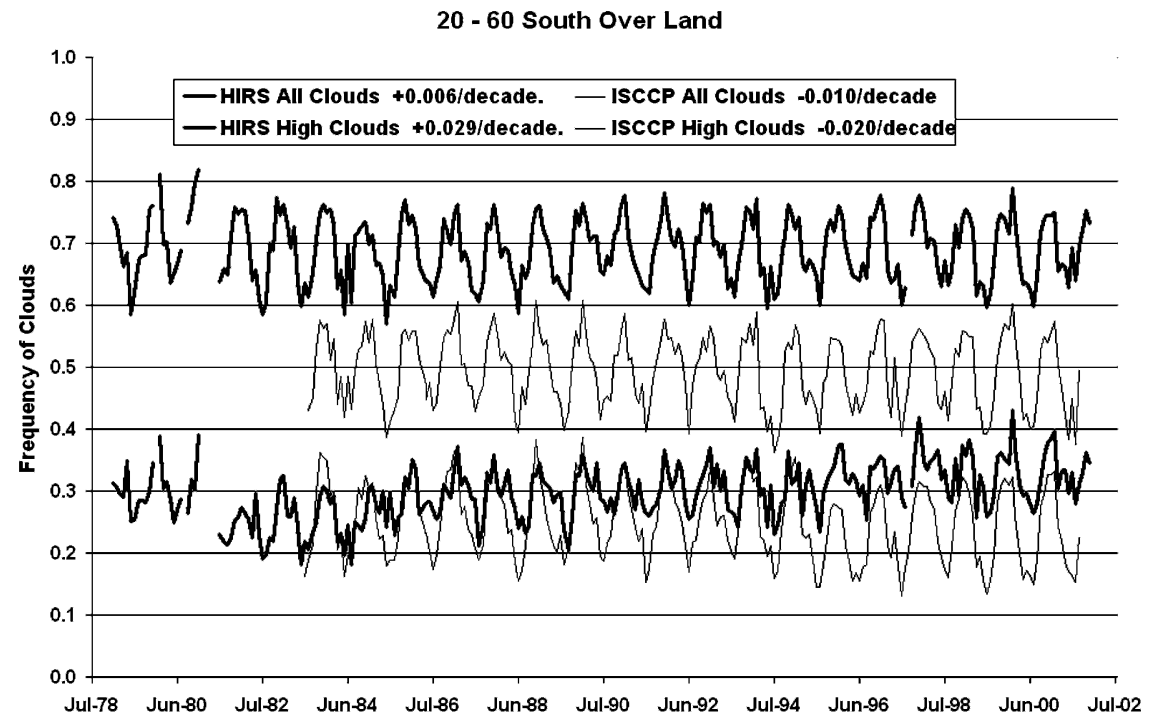

FIG. 8. The monthly average frequency of clouds from $20^{\circ}$ to $60^{\circ} \mathrm{S}$ over land. 


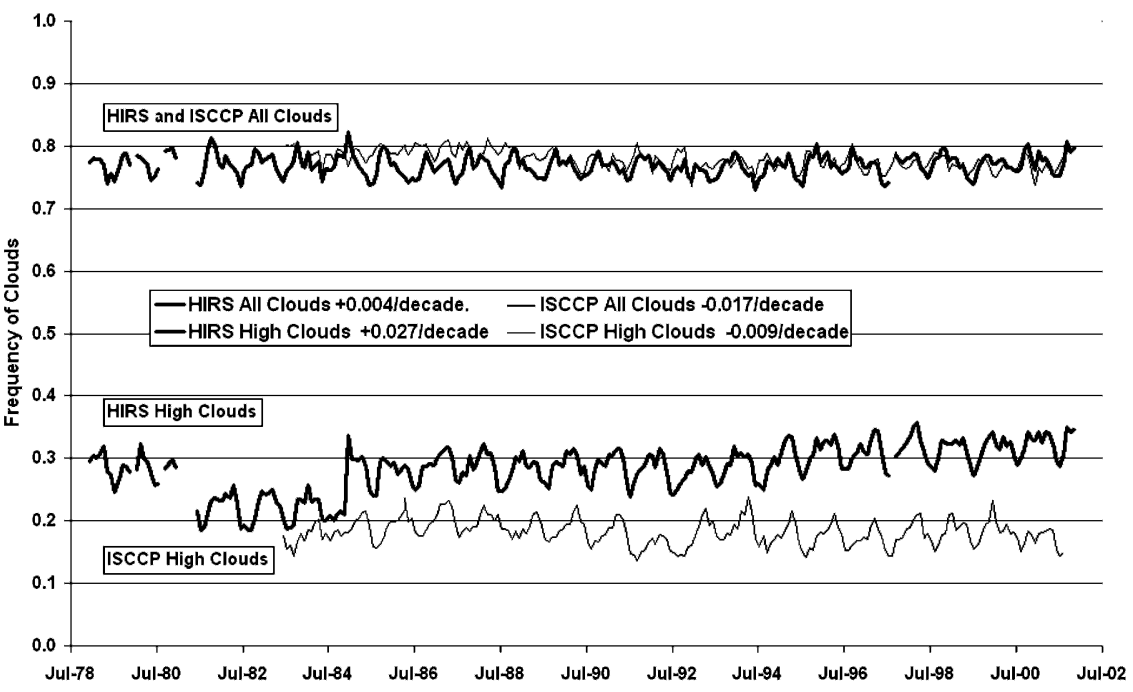

FIG. 9. Same as in Fig. 8, but over oceans.

The corrections to the HIRS data had only minor effects on the calculated trends. Table 5 also shows the trends (1985-2001) for the data before applying the orbit drift and $\mathrm{CO}_{2}$ change corrections. The corrections increased the high-cloud trends slightly in the Northern
Hemisphere by 0.006 decade $^{-1}$ on the average but decreased the trends in the Tropics and Southern Hemisphere up to 0.008 decade $^{-1}$. This occurred because the orbit drift correction was often opposed to the $\mathrm{CO}_{2}$ correction.

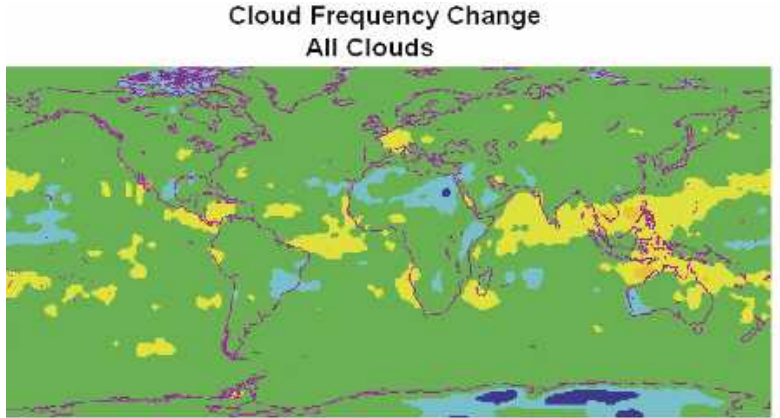

High Clouds

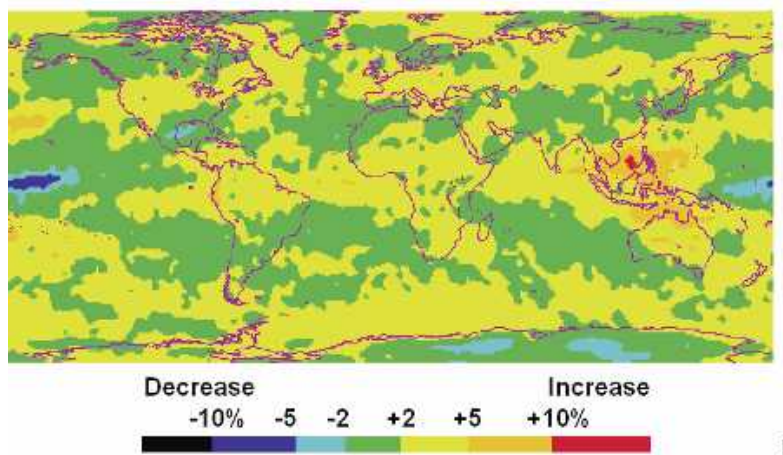

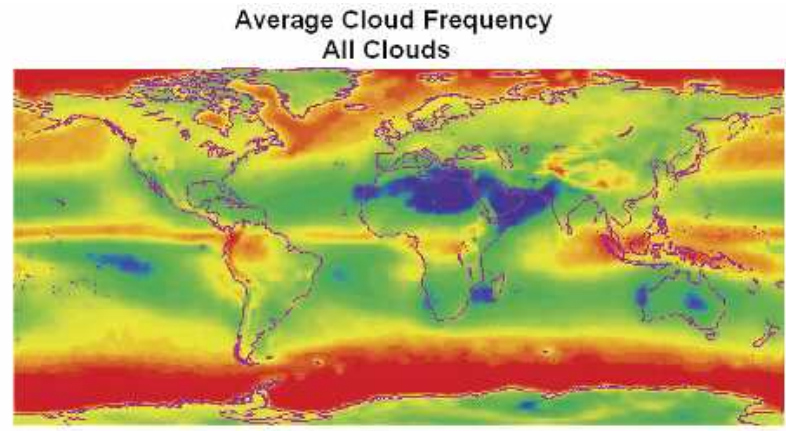

High Clouds

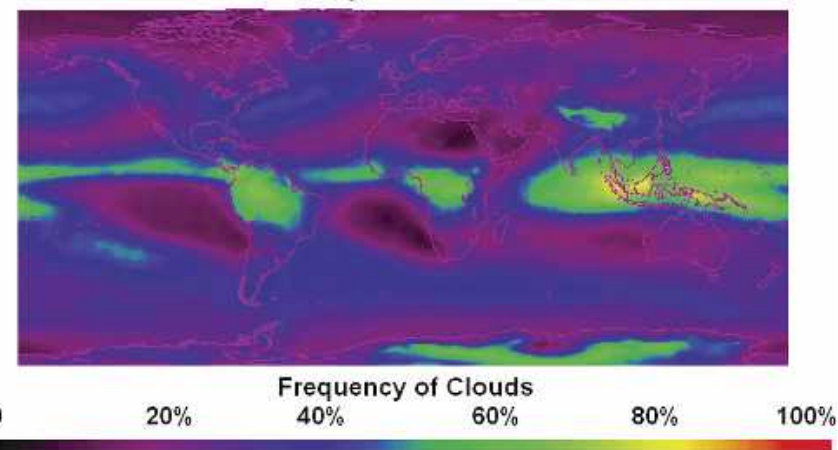

FIG. 10. The geographical locations of changes in all-cloud and high-cloud frequency between the first and last $8 \mathrm{yr}$ of this study (1994-2001 minus 1985-92). 


\section{Summary and conclusions}

The UW NOAA Pathfinder HIRS analysis finds the following:

1) Total cloud cover remains relatively steady over the 22 yr studied, with roughly $75 \%$ of all HIRS observations indicating clouds.

2) High clouds are observed in one-third of the HIRS observations. High-cloud cover shows an annual cycle mainly over land with the maximum in the summer of each hemisphere. In tropical land areas, the maximum is from December to February.

3) The trends in cloud cover are small and disagree with the ISCCP. The HIRS indicates no significant trends in total cloud cover but a slight increasing trend in high cloud cover of 0.02 (or $2 \%$ ) decade de $^{-1}$ in midlatitudes. In the Tropics, a trend in high clouds is found only over oceans. The ISCCP shows decreasing trends in total cloud cover of 0.03 to 0.04 decade ${ }^{-1}$ but little high-cloud trend except for slight decreases in midlatitude land areas in both hemispheres. Campbell and Vonder Haar (2005) have examined the ISCCP monthly summaries and suggest that increasing satellite coverage in later years (and hence more nadir viewing coverage) may be influencing the ISCCP trends.

4) Volcanic eruptions as well as El Niño-Southern Oscillation events in the past $20 \mathrm{yr}$ do not seem to influence the global HIRS cloud-detection trends significantly.

5) HIRS finds more cloud cover and high clouds than ISCCP. This is consistent with the previous comparison of the earlier UW HIRS data with the ISCCP in Jin et al. (1996); they find the UW HIRS analysis reporting $10 \%-15 \%$ more upper-tropospheric thin clouds than the ISCCP.

The most significant differences between this UW NOAA Pathfinder HIRS analysis and the ISCCP lie in the methods used to detect upper-tropospheric transmissive cirrus clouds and to estimate their heights. The ISCCP uses visible reflectance measurements with the infrared window thermal radiance measurements. This limits transmissive cirrus detection to only daylight data. The UW NOAA Pathfinder HIRS analysis uses only longwave infrared data from 11 to $15 \mu \mathrm{m}$, which is more sensitive to transmissive cirrus clouds. It finds more upper-tropospheric clouds than the ISCCP different time trends because of the inclusion of these clouds.

Acknowledgments. The views, opinions, and findings contained in this report are those of the author(s) and should not be construed as an official National Oceanic and Atmospheric Administration or U.S. government position, policy, or decision. The analysis of these data was partially funded by NOAA Grant NA06GP0307 and NASA Contract NAG1-2196.

\section{REFERENCES}

Campbell, G. G., and T. H. Vonder Haar, 2005: Global cloudiness: Nearly constant in time from ISCCP observations. Science, in press.

Jackson, D. L., and J. J. Bates, 2001: Upper tropospheric humidity algorithm assessment. J. Geophys. Res., 106, 32 259-32 270.

Jin, Y., W. B. Rossow, and D. P. Wylie, 1996: Comparison of the climatologies of high-level clouds from HIRS and the ISCCP. J. Climate, 9, 2850-2879.

McMillin, M., L. J. Crone, T. J. Kleespies, 1995: Atmospheric transmittance of an absorbing gas. 5. Improvements to the OPTRAN approach. Appl. Opt., 34, 8396-8399.

Rossow, W. B., and R. A. Schiffer, 1999: Advances in understanding clouds from the ISCCP. Bull. Amer. Meteor. Soc., 80, 2261-2287.

Schiffer, R. A., and W. B. Rossow, 1983: ISCCP: The first project of the World Climate Research Program. Bull. Amer. Meteor. Soc., 64, 770-784.

Stubenrauch, C. J., A. Chedin, R. Armante, and N. A. Scott, 1999a: Clouds as seen by satellite sounders (3I) and imagers (ISCCP). Part II: A new approach for cloud parameter determination in the 3I algorithm. J. Climate, 12, 2214-2223.

- W. B. Rossow, F. Cheruy, A. Chedin, and N. A. Scott, 1999b: Clouds as seen by satellite sounders (3I) and imagers (ISCCP). Part I: Evaluation of cloud parameters. J. Climate, 12, 2189-2213.

Wylie, D. P., and W. P. Menzel, 1999: Eight years of high cloud statistics using HIRS. J. Climate, 12, 170-184.

- - , and H. M. Woolf, 2002: The diurnal cycle of uppertropospheric clouds measured by GOES-VAS and the ISCCP. Mon. Wea. Rev., 130, 171-179.

_ W. W. P. Menzel, and K. I. Strabala, 1994: Four years of global cirrus cloud statistics using HIRS. J. Climate, 7, 1972-1986. 